Journal of Economics and Behavioral Studies

Vol. 4, No. 5, pp. 297-306, May 2012 (ISSN: 2220-6140)

\title{
Cultural Characteristics and Negotiation Styles
}

\author{
Yu-Te Tu \\ Chungyu Institute of Technology, Taiwan \\ suntu@ms18.hinet.net
}

\begin{abstract}
Numerous factors can affect the results of the negotiating process. Successful negotiation not only requires acquiring technical communicative abilities, but also an understanding of the cultural context of the negotiation by both parties. Due to its size and rapid economic development, China has become an increasingly important factor for world economy and growth. Until recently, conducting business in China has been a challenging and sometimes futile venture for businesses trying to break into this lucrative market because China's government has maintained very strict rules for the import of goods and services for resale to China, while widely exporting Chinese goods and services. The approach uses Casse and Deols' model and cultural factors including education, religion and degrees of individualism/collectivism to be the dependent and independent variables. Data were collected from public companies listed on the stock exchanges of China by means of an online survey method. Structural equation modeling was used to test hypothesized models and hypotheses of research. The findings show that education, religion and degrees of individualism/collectivism affects the style of negotiation. These findings could be useful in the application of a specific set of values and attitudes that relate to regional cultural attributes, and develop better negotiation skills by providing insights into the nuances of international negotiations. The researcher suggests that the negotiators still need to be trained in body language, strategies, temper control, international manners, and customs. A better knowledge of negotiation should be helpful in understanding business and in realizing which negotiation styles are most appropriate for a particular country.
\end{abstract}

\section{Keywords: Cultural characteristics, negotiation styles}

\section{Introduction}

Differences in negotiating styles originate from the fact that every society places different degrees of importance on "relationship development, negotiating strategies, decision making methods, spatial and temporal orientations, contracting practices, and illicit behaviors such as bribery" (Acuff, 1997). Successful negotiation not only requires acquiring technical communicative abilities, but also an understanding of the context of the negotiation by both parties (Korobkin, 2000). Different cultures use different negotiation styles, and a party's style in negotiating directly impacts the terms of the final agreement. It is important to understand the various negotiation styles and the cultural issues that influence behavior during negotiation. Numerous factors can affect the results of the negotiating process. A few of these include culture, personality, gender, experience, knowledge, and education of the parties involved in the negotiation process. Obtaining information about the other parties, and being aware of their cultural differences becomes extremely helpful to negotiating effectively. No one should enter into any negotiations without preparation, because a lack of preparation could result in losing the deal. Due to its size and rapid economic development, China has become an increasingly important factor for world economy and growth. Until recently, conducting business in China has been a challenging and sometimes futile venture for businesses trying to break into this lucrative market because China's government has maintained very strict rules for the import of goods and services for resale to China, while widely exporting Chinese goods and services. Although a growing number of companies have established businesses in China, it is still difficult to conduct business with China and to negotiate effectively. Within this increasing global economic interdependence, the topic of negotiation has been identified as an area requiring further inquiry. At present, studies comparing the impact of culture on negotiation between two countries are being developed. Many scholars consider culture an important factor in affecting negotiation styles (Fan \& Zigang, 2004; Woo \& Prud'homme, 1999; Chua \& Fujino, 1999; Whitcomb, Erdener, \& Cheng, 1998). Some studies are cross-sectional, emphasizing the impact of cultural differences on negotiation styles--like Volkema and Fleurv (2002), examining the impact of culture on American and 
Brazilian negotiation styles, and Lee (2000) examining the impact of culture on American and Chinese negotiation styles. Some authors contrast and focus on negotiation styles of specific countries (Morris, Ettkin, \& Helms, 2001). Other well-known theories have guided practice and research concerning the importance of cross-cultural differences over the past years. Examples of these include the negotiation process model, the zone definition/surplus allocation dichotomy, and Hofstede's cultural dimension model. The research aims to investigate the role of culture in shaping negotiation style of people in China.

\section{Literature Review}

Culture: Barbash and Taylor (1997) indicated that culture includes religion, gender, language, class, ethnicity, and sexual orientation. Since sub-cultures, cultures and super-cultures merge and evolve, while being less bounded than before; the idea of culture is more porous and varied than before (Barbash \& Taylor, 1997). "Culture is defined as a set of shared values and beliefs that characterize national, ethnic, moral and other group behavior" (Faure \& Sjostedt, 1993). One further definition of culture was put forth by Schein as a pattern of shared basic assumptions that a group learned as it solved its problems of external adaptation and internal integration, that has worked well enough to be considered valid and, therefore be taught to new members as the appropriate way to perceive, think, and feel with relation to those problems (Schein, 1997). Simintiras and Thomas (1998) defined cultures as accepted values and norms that influence the way in which people think, feel, and behave. D'Andrade (1965) presents a slightly more comprehensive interpretation of culture: Learned systems of meaning, communicated by means of natural language and other symbol systems...capable of creating cultural entities and particular senses of reality. Through these systems of meaning, groups of people adapt to their environment and structure interpersonal activities.... Cultural systems can be defined as a very large diverse pool of knowledge, or shared clusters of norms, or subjectively shared, symbolically created realities (p. 116).

Negotiation: The negotiation process between the buyer and the seller is a very important matter (Neslin \& Greenhalgh, 1983), and achieving success in negotiation is one of the most challenging communicative tasks in business (Gilsdorf, 1997). In the broadest sense, negotiation is a process of communicating back and forth to discuss the issues to reach an agreement that is satisfactory to all parties involved (Foroughi, 1998; Gulbro \& Herbig, 1994). In 1994, Delivre's theoretical literature (as cited in Demers, 2002) indicated that: Negotiation is a process for managing disagreements with a view to achieving contractual satisfaction of needs. Negotiation is a process, that is, a method that consists of a number of steps. A method for managing disagreements, because the two parties could not initially agree to satisfy their needs to their mutual satisfaction. It is therefore desirable to achieve contractual satisfaction. (p. 35). Negotiation is a kind of social interaction for reaching an agreement for two or more parties, with different objectives or interests that they think are important (Manning \& Robertson, 2003; Fraser \& Zarkada-Fraser, 2002). Gulbro and Herbig (1999) indicated that in order to achieve successful agreements, negotiations are important in order to eliminate competing points of view between the representatives of both parties. Each party's individual culture will determine its way of thinking, values, norms and behaviors (Simintiras \& Thomas, 1998; Hung, 1998; Woo \& Pru'homme, 1999). Gulbro and Herbig (1994) indicated that different cultures could generate distinct negotiation styles. These different styles in business negotiation are the product of differences in communication, protocols, persuasion strategies, and personal characteristics, including accommodation, determination, flexibility, and adaptation (Hung, 1998).

Culture and Business Negotiations: Numerous studies have shown that culture is one of most important factors in negotiations. An understanding of the differences and similarities of each culture by the negotiators is beneficial in facilitating communication and success in negotiation (Gannon, 2001). Due to the sophistication and knowledge required by these exchanges, many negotiators are unsuccessful in reaching agreements because of cultural issues as opposed to economic or legal problems (Gulbro \& Herbig, 1995). During these negotiations, both parties must often change their tactics to meet the other party's style. With the goal of helping individuals distinguish the various cultural differences of individual countries, Hofstede (1980) introduced his seminal theory of four cultural dimensions based on his earlier qualitative, phenomenological studies. This theory identifies four major variables of cultural differences--power, uncertainty/avoidance, individualism/collectivism characteristics, and masculinity/femininity (Hofstede, 1994 \& 1980). Among the five cultural dimensions, individualism/collectivism characteristics are the most 
often employed in cross-cultural studies of negotiation (Bazerman, Curhan, Moore, \& Valley, 2000). Hofstede and Bond (1988) added a fifth dimension to the cultural dimension model, identified as Confucian dynamism, to make a distinction between Chinese and Western cultural values. The cultural dimensions were defined by Barry (2001) as follows: Power difference is the perceived degree of inequality among people. Uncertainty avoidance is the extent to which a society feels threatened by uncertain situations and avoids these situations by providing stable systems with formal rules. Individualism/Collectivism characteristics are a social fabric in which each individual takes care of himself or herself in contrast with collectivism in which groups take care of the individual. Masculinity-Femininity reflects on whether the dominant values that are associated with the collection of money and things (masculinity) as contrasted with values associated with caring for others and quality of life (femininity). Confucian dynamism reflects whether the members of a society are short-term or long-term oriented in outlook. (p. 35). In order to test the practical applications of Hofstede's theory, Gulbro and Herbig (1999) conducted a study about cultural differences in the process of conducting negotiations. The study has consisted of a non-experimental, causal comparative, quantitative design. A thousand surveys were randomly mailed to various U.S. companies whose names and addresses were in export directories. Two hundred additional surveys were sent randomly to multinational companies, and included Chinese, Latin American, French/Italian, Japanese, and German companies in the US. The five groups were chosen due to their similarity to the cultures discussed by Hofstede's earlier study. Gulbro and Herbig's literature review highlighted a gap in the existing research about the effects of Hostfede's four cultural dimensions on cross-cultural negotiation. To address this need, Gulbro and Herbig (1999) designed the following study.

Random sampling resulted in a self-selected, data-producing sample of 60 participants with a response rate of $20 \%$. During the analysis, Chi square was used to measure differences across organizations, and $t$-tests as well as ANOVA were used to measure mean differences for specific questions. These tests revealed that reliability estimates were internally consistent, and that the study's construct and criterion were valid. Gulbro and Herbig's (1999) interpretation of the findings led to the following conclusions: 1 ) high levels collectivism of will result in more time spent on indirect activities unrelated to the negotiations; 2) high levels of individualism result in more time spent conducting direct negotiations; 3) with higher power differences, individuals will spend less time trying to reach a compromise; 4) with a high level of femininity more time will be spent in the act of persuasion; 5) with lower uncertainty avoidance less time will be spent trying to reach an agreement; and 6) in individualistic cultures less time will be spent on the planning and debriefing for negotiations than in collective cultures. Janosik (1987) introduced his seminal theory of cross-cultural negotiation research based on his qualitative, phenomenological studies to find the relationship between culture and negotiation. The theory also provides that no matter which approach to negotiation be applied, it is still important to understand individual variations in negotiation styles when parties attempt to negotiate cross-culturally. Janosik (1987) identified the following four approaches to identifying and classifying culture: 1) cultures as learned behaviors; 2) cultures as systems of shared values; 3) cultures as dialectics; and 4) culture in contexts, defined as cross-cultural negotiation research. Several subsequent empirical studies by Osman-Gani and Tan led to refinement of the theory. Through these studies, the researchers verified the propositions about different negotiation styles in different cultures. Lately, the theory has been adapted to fit cross-cultural business negotiations involving Asian managers. In one study, Osman-Gani and Tan (2002) conducted an exploratory quantitative study of cross-cultural impacts on negotiation styles of Chinese, Malay, and Indian managers living in Singapore. Their literature review comprehensively examined research relating to the effect of culture on the process of negotiation. Noting the shortcomings of existing research, Osman-Gani and Tan designed their study to test Janesik's propositions with regard to cross-cultural negotiation. This study was based on a model that uses four styles of negotiation as dependent variables, which was developed by Casse and Deol (1985). These negotiation styles were defined by Osman-Gani and Tan as follows: A factual style identifies facts in an unemotional manner, pays attention to details and all statements made during a negotiation, and places much importance on proof and facts as related to experience. An intuitive person is warm and animated when making statements, flexible and creative during negotiations, fluid and able to adapt to changing subjects and situations, and imaginative in projecting into the future. A normal person considers and weights facts according to a set of personal values; this person uses all the tools at his or her disposal, such as emotions, status, authority, and rewards, to come up with the best bargain. The analytical negotiator is strongly logical, tries to find cause-and-effect in all issues, and likes to weigh pros and cons thoroughly (825). 


\section{Methodology}

For the study, a stratified random sample of 600 people was selected to be surveyed. Of those selected, there were 300 Chinese managers, 150 Indian managers, and 150 Malay managers. Reliability estimates were drawn from 30 personal interviews with selected managers from the three cultural groups. The interviews were initially conducted to solicit the managers' views on negotiation strategies as well as on the relevance of the questionnaire items for initial consistency. From this, construct and criterion-related validity were established. The study's value lies in its ability to help people understand the similarity of negotiation styles among Chinese, Malay, and Indian managers in Singapore. Osman-Gani and Tan's analysis of the results did not reveal a large difference between the three groups in their negotiations when comparing intuitive, normative, analytical, and factual styles. Total mean scores for each group, based on the four negotiation styles, were as follows: 1 ) factual (Chinese $=54.75$, Malay $=54.45$ and Indian $=53.25$ ); 2 ) analytical (Chinese $=58.35$, Malay $=57.15$ and Indian $=55.5) ; 3$ ) normative (Chinese $=48.3$, Malay $=50.55$ and Indian $=51.9$ ); and 4) intuitive (Chinese $=51.6$, Malay $=53.85$ and Indian $=50.85$ ). Overall, these results can help people understand that there are similar negotiation styles among Chinese, Malay, and Indian managers. Aside from that, they can assist Singaporean managers in their interaction with Chinese, Malay, and Indian managers. These findings led to the researchers' conclusion that Chinese, Malay, and Indian managers in Singapore have no significant differences in negotiation styles. One limitation reported by Osman-Gani and Tan (2002) was that the sample population focused solely on managers. They offered the following areas for future study: 1) a comparison of the Chinese managers in Singapore with the Chinese managers in Hong Kong, Taiwan, Mainland China, Indonesia, and Malaysia; and 2) an extension of the study to include different respondents, such as employees or with other professional groups such as lawyers, doctors, and accountants.

The study employed a non-experimental, quantitative research design to analyze cultural characteristics affect negotiation styles. The dependent variables of the model employed in this research are the four negotiation styles. The individualistic-collectivist characteristic is one of the independent variables. Other independent variables reflecting cultural differences will include education and religion. The research model and hypotheses are as follows:

\section{Figure 1: Research Model}

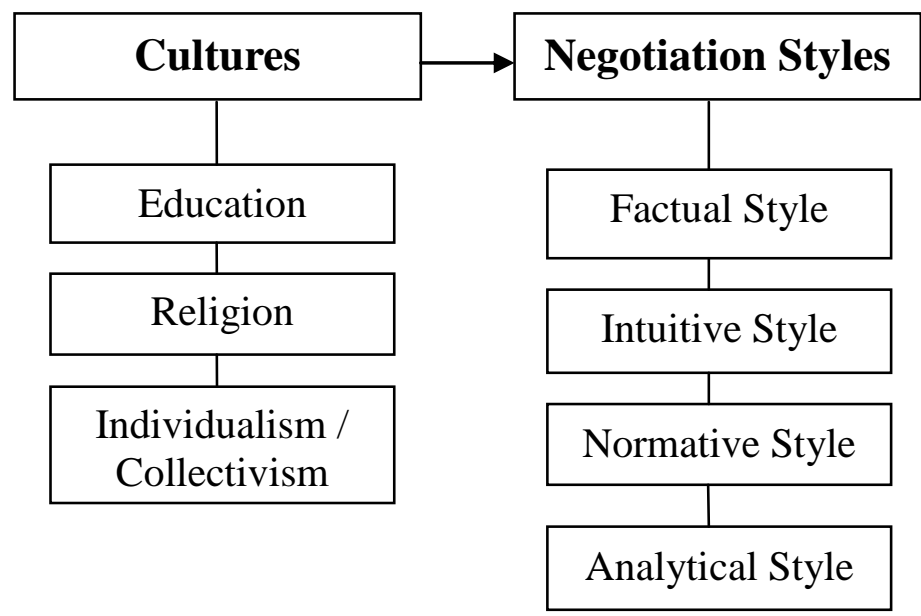

H1: The cultural characteristics significantly affect the factual negotiation style.

H2: The cultural characteristics significantly affect the intuitive negotiation style.

H3: The cultural characteristics significantly affect the normative negotiation style.

H4: The cultural characteristics significantly affect the analytical negotiation style.

Population and Sampling Plan: For this study, the accessible population was chosen from public companies listed under the Shenzhen Stock Exchange (SSE) and Shanghai Stock Exchange in China. There were 585 listed companies (including stock A: 530 companies and Stock B: 55 companies) in the Shenzhen Stock Exchange (SSE), and all companies are classified into six sectors, including industry, business, financials, real estate, 
utilities, and others. There were 872 listed companies (including stock A: 820 companies and Stock B: 52 companies) in the Shanghai Stock Exchange, and all companies were classified into five sectors, including industry, business, real estate, utilities, and others. In order to avoid sampling errors, the population was collected from different sectors of stock markets in the three regions. Overall, this method for determining a sample population is more accurate than purely random sampling, further it allows the researcher to select a sample that accurately reflects the diverse sectors and characteristic patterns in the desired population (Walled \& Fraenkel, 2001). All information, such as the names of CEOs and sales and purchase managers, and e-mail addresses of listed companies were obtained through the website of the Shenzhen Stock Exchange (SSE), and Shanghai Stock Exchange. The survey was accessible on the Internet without direct contact with the researcher. The CEOs and sales and purchase managers of the sample population were invited to participate via an e-mail that explained the research and included a link to the survey website. The questionnaire was posted on the website, "www.my3q.com" in English, traditional Chinese, and simplified Chinese, and asked respondents to return the surveys within 30 days.

Instrumentation: A three-part questionnaire was used to measure variables. Demographic variables of the questionnaire for the first part were developed by the researcher, and included gender, education background, work experience, religion, age and years of residence in foreign countries. Gender was defined as a dichotomous variable (1=Male; $2=$ Female). Education was defined as a nominal variable $(1=$ High School Diploma or Equivalent; 2= Associate Degree; 3= Bachelor Degree; 4= Graduate Degree). Religion was defined as a nominal variable ( $1=$ Buddhist; $2=$ Christian; $3=$ Muslim; $4=$ Others). For the second part, questions designed to examine the Individualism/Collectivism characteristics of an individual. The dependent variables of the model employed in this research were the four negotiation styles developed in 1985 by Dr. Pierre Casse and Dr. Surinder Deol--factual negotiation, intuitive negotiation, normative negotiation, and analytical negotiation. Questions designed to examine each negotiation style. Response categories were set on a five-point Likert-type scale that was analyzed on a five-point Likert-type scale. There were five options for each statement, with scoring as follows: $5=$ "Always" (around 100\% of the time); $4=$ "Often" (around 75\% of the time); $3=$ "Occasionally" (around 50\% of the time); $2=$ "Seldom" (around 25\% of the time); and 1="Never" (around $0 \%$ of the time). The Statistics Package of Social Science (SPSS) for Windows version 13.0 was utilized to report coefficient alphas for modified instruments in order to address reliability and validity of the instrument, and multiple regression analysis was used to test hypotheses. The regression models below indicate what variables are going to be tested:

\author{
To test dimension of Factual style: \\ NSFS $=a+b 1 E+b 2 R+b 3 I / C$ \\ To test dimension of Intuitive style: \\ NSIS $=\mathrm{a}+\mathrm{b} 1 \mathrm{E}+\mathrm{b} 2 \mathrm{R}+\mathrm{b} 3 \mathrm{I} / \mathrm{C}$ \\ To test dimension of Normative style: \\ NSNS $=a+b 1 E+b 2 R+b 3 I / C$ \\ To test dimension of Analytical style: \\ NSAS $=a+b 1 E+b 2 R+b 3 I / C$ \\ NSFS=Negotiation style (Factual style) \\ NSIS=Negotiation style (Intuitive style) \\ NSNS=Negotiation style (Normative style) \\ NSAS=Negotiation style (Analytical style) \\ $\mathrm{E}=$ Education \\ $\mathrm{R}=$ Religion \\ $\mathrm{I} / \mathrm{C}=$ Degree of Individualism/Collectivism Characteristics
}

\title{
4. Results
}

The internal consistency reliability was measured by using Cronbach's coefficient $a$ according to the mean or average correlation of each item with every other item. Initially, the internal consistency reliability of the individualist/collectivist characteristics and four negotiation styles were assessed and the reliability coefficients of each subscale as follows: 1 ) individualist/collectivist characteristics (10 items); Cronbach $\alpha=0.74 ; 2$ ) analytical negotiation styles (18 items): Cronbach $\alpha=0.87$; 3) normative negotiation styles 
(18 items): Cronbach $\alpha=0.75 ; 4)$ factual negotiation styles (18 items): Cronbach $\alpha=0.85$; and 5) intuitive negotiation styles (18 items): Cronbach $\alpha=0.82$. Lin (2006) states that Cronbach is $a$ value in basic research should be at least 0.80 . For higher internal consistency reliability, four questions were removed from the questionnaire of individualist/collectivist characteristics, and the Cronbach's $a$ value became 0.81 . Eight questions were removed from the questionnaire of each negotiation style. The analytical negotiation style Cronbach is $a$ value became 0.92 ; the questionnaire of normative negotiation style Cronbach is $a$ value rose to 0.87; the Cronbach's $a$ value increased to 0.88; and the questionnaire of intuitive negotiation style Cronbach is $a$ value became 0.86. The Kaiser-Meyer-Olkin (KMO) test and Bartlett's test had to be examined before performing factor analysis. According to Lin (2006), a KMO value larger than 0.50 is acceptable, and in 2005, Leech, Barrett, and Morgan found that Bartlett's test should be significant. The KMO value for the variables used in the study was 0.54, and Bartlett's test was significant, which means all negotiation styles in this study were sufficient for social science research and factor analysis, and could therefore be performed. For the Negotiation Style Questionnaire, 40 items were examined by principal axis factor analysis. These items were categorized into four negotiation styles. Each negotiation style was combined with several items that participants needed to respond to in the questionnaire. Goodwin and Goodwin (1999) indicated that if a factor loading is less than 0.30 , the variable should not be considered a part of the factor. All of the factor loadings in the study were above 0.30 , indicating that the construct validity was acceptable. 2,187 invitation e-mails were sent. There were 281 returned, and only 262 were useful. $213(81.3 \%)$ were male and 49 (18.7\%) were female. In this study, 15 respondents (5.7\%) held a high school diploma or equivalent; no respondents had an associate degree; 164 respondents (62.6\%) were college or university graduates; and 83 respondents (31.7\%) had a graduate degree. In terms of religion, 21 respondents (8.0\%) were Buddhist; there were no Christian; 33 (12.6\%) were Muslim; and 208 (79.4\%) were others.

H1: The cultural characteristics significantly affect the factual negotiation style.

Table 1 depicts the results of $F(3,258)=7.645, p<0.01$, and the $R^{2}$ value were 0.08 , which meant that this model explained $8 \%$ of the variance on the factual negotiation style. The factor of individualist/collectivist characteristics had a negative influence on the factual negotiation style, and the individualist/collectivist characteristics did not significantly predict the factual negotiation style from the whole set of predictors. The prediction model on the factual negotiation style was follows: Factual style $=1.734+0.191$ (Education) +0.267 (Religious Beliefs)-0.042 (Individualism/Collectivism)

Table 1: Hierarchical Multiple Regression Coefficients of Factual Negotiation Style

\begin{tabular}{|c|c|c|c|c|c|c|c|c|c|}
\hline & $\alpha$ & $B$ & $\begin{array}{l}\text { Std. } \\
\text { Er. }\end{array}$ & Std. $\beta$ & $\mathbf{t}$ & $F$ & $\begin{array}{l}\text { Df of } \\
\text { Regression }\end{array}$ & $\begin{array}{l}D f \quad \text { of } \\
\text { Residual }\end{array}$ & $\mathbf{R}^{2}$ \\
\hline (Constant) & 1. 734 & & & & & \multirow{4}{*}{$7.645^{* * *}$} & \multirow{4}{*}{3} & \multirow{4}{*}{258} & \multirow{4}{*}{0.082} \\
\hline $\begin{array}{l}\text { Education } \\
\text { Level }\end{array}$ & & 0.19 & 0.069 & 0.17 & 2. $765^{* *}$ & & & & \\
\hline $\begin{array}{l}\text { Religious } \\
\text { Beliefs }\end{array}$ & & 0.27 & 0.059 & 0.29 & 4. $505^{* * *}$ & & & & \\
\hline $\begin{array}{l}\text { Individualism/ } \\
\text { Collectivism }\end{array}$ & & -0.04 & 0.212 & -0.01 & -0.198 & & & & \\
\hline
\end{tabular}

\section{H2: The cultural characteristics significantly affect the intuitive negotiation style.}

Table 2 depicts the results of $F(3,258)=7.217, p<0.001$, and the $R^{2}$ value were 0.08 , which meant that the model explained $8 \%$ of the variance on the intuitive negotiation style. The factor of education had a negative influence on the intuitive negotiation style, and the education did not significantly predict the intuitive negotiation style from the whole set of predictors. The prediction model on the intuitive negotiation style was as follows: Intuitive style=1.739-0.042(Education) +0.083 (Religious Beliefs) +0.305 (Individualism/Collectivism). 
Table 2: Hierarchical Multiple Regression Coefficients of Intuitive Negotiation Style

\begin{tabular}{|c|c|c|c|c|c|c|c|c|c|}
\hline & $\alpha$ & $\boldsymbol{B}$ & $\begin{array}{l}\text { Std. } \\
\text { Er. }\end{array}$ & Std. $\beta$ & $\mathbf{t}$ & $F$ & $\begin{array}{l}\text { Df of } \\
\text { Regression }\end{array}$ & $\begin{array}{l}D f \quad o f \\
\text { Residual }\end{array}$ & $\mathbf{R}^{2}$ \\
\hline (Constant) & 1. 739 & & & & & & & & \\
\hline $\begin{array}{l}\text { Education } \\
\text { Level }\end{array}$ & & -0.04 & 0.038 & -0.07 & -1.115 & & & & \\
\hline $\begin{array}{l}\text { Religious } \\
\text { Beliefs }\end{array}$ & & 0.08 & 0.032 & 0.16 & $2.573 *$ & 7. $217^{* * *}$ & 3 & 258 & 0.077 \\
\hline $\begin{array}{l}\text { Individualism/ } \\
\text { Collectivism }\end{array}$ & & 0.31 & 0.115 & 0.16 & 2. $648^{* *}$ & & & & \\
\hline
\end{tabular}

\section{H3: The cultural characteristics significantly affect the normative negotiation style.}

Table 3 depicts the results of $F(3,258)=29.059, p<0.001$, and the $R^{2}$ value was .25 , which meant that the model explained $25 \%$ of the variance on the normative style. The factor of individualism/collectivism characteristics had a negative influence on the normative negotiation style, and the factor of education did not significantly predict to the model for predicting the normative negotiation style. The prediction model on the normative negotiation style was as follows: Normative style $=5.027+0.016$ (Education) +0.157 (Religious Beliefs)-0.631 (Individualism/Collectivism)

Table 3: Hierarchical Multiple Regression Coefficients of Normative Negotiation Style

\begin{tabular}{|c|c|c|c|c|c|c|c|c|c|}
\hline & $\alpha$ & $B$ & $\begin{array}{l}\text { Std. } \\
\text { Er. }\end{array}$ & Std. $\beta$ & $\mathbf{t}$ & $F$ & $\begin{array}{l}\text { Df of } \\
\text { Regression }\end{array}$ & $\begin{array}{l}D f \quad o f \\
\text { Residual }\end{array}$ & $\mathbf{R}^{2}$ \\
\hline (Constant) & 5. 027 & & & & & \multirow{4}{*}{$29.06^{* * *}$} & \multirow{4}{*}{3} & \multirow{4}{*}{258} & \multirow{4}{*}{0.253} \\
\hline $\begin{array}{l}\text { Education } \\
\text { Level }\end{array}$ & & 0.02 & 0.027 & 0.03 & 0.557 & & & & \\
\hline $\begin{array}{l}\text { Religious } \\
\text { Beliefs }\end{array}$ & & 0.16 & 0.02 & 0.39 & 6. $736^{* * *}$ & & & & \\
\hline $\begin{array}{l}\text { Individualism/ } \\
\text { Collectivism }\end{array}$ & & -0.63 & 0.083 & -0.42 & $-7.565^{* * *}$ & & & & \\
\hline
\end{tabular}

\section{H4: The cultural characteristics significantly affect the analytical negotiation style.}

Table 4 depicts the results of $F(3,258)=7.858, p<0.001$. The $R^{2}$ value was 0.08 , which meant that the model explained $8 \%$ of the variance on the analytical negotiation style. all the factors had a negative influence on the analytical negotiation style, and the religious beliefs and individualist/collectivist characteristics did not significantly predict the analytical negotiation style from the whole set of predictors. The prediction model on the analytical style was as follows: Analytical style=5.452-0.228(Education)-0.061(Religious Beliefs) -0.184 (Individualism/Collectivism). 
Table 4: Hierarchical Multiple Regression Coefficients of Analytical Negotiation Style

\begin{tabular}{|c|c|c|c|c|c|c|c|c|c|}
\hline & $\alpha$ & $\boldsymbol{B}$ & $\begin{array}{l}\text { Std. } \\
\text { Er. }\end{array}$ & Std. $\beta$ & $\mathbf{t}$ & $\boldsymbol{F}$ & $\begin{array}{l}\text { Df of } \\
\text { Regression }\end{array}$ & $\begin{array}{l}D f \quad o f \\
\text { Residual }\end{array}$ & $\mathbf{R}^{2}$ \\
\hline (Constant) & 5.45 & & & & & \multirow{4}{*}{ 7. $858^{* * *}$} & \multirow{4}{*}{3} & \multirow{4}{*}{258} & \multirow{4}{*}{0.084} \\
\hline $\begin{array}{l}\text { Education } \\
\text { Level }\end{array}$ & & -0.228 & 0.05 & -0.294 & $-4.71^{* * *}$ & & & & \\
\hline $\begin{array}{l}\text { Religious } \\
\text { Beliefs }\end{array}$ & & -0.061 & 0.04 & -0.093 & -1.46 & & & & \\
\hline $\begin{array}{l}\text { Individualism/ } \\
\text { Collectivism }\end{array}$ & & -0.184 & 0.15 & -0.075 & -1.24 & & & & \\
\hline
\end{tabular}

\section{Conclusion}

The results indicated that education and religious beliefs significant affect factual negotiation style; religious beliefs and individualistic/collectivist attitudes significant affect intuitive and normative negotiation styles, and education significant affects analytical negotiation style among individuals from China. Other variables do not significant affect business negotiation styles among individuals from China. In China, Russian was the dominant foreign language during the initial years of the People's Republic (Bray \& Qin, 2001). Because social policies at that time were closely guided by the Soviet Union, much of the education system, especially the university sector, was restructured along Soviet lines (Hayhoe, 1999). Gu (2001) indicated that China is a socialist country directed by the Karl Marx and Mao Zedong, while Taiwan and Hong Kong had never stressed Marxism and Maoism (Bray \& Qin, 2001). Buddhism came to Mainland China from India (called Mahayana Buddhism) in the 1st century AD, and spread to Taiwan during the Ming dynasty. Boyle and Sheen (1997) indicated that during the period of 1949 to 1956, religious groups were encouraged to organize under state control in China, and atheism was spread vigorously during this time. This trend worsened during the Cultural Revolution from 1966 to 1976, with widespread discrimination against believers and attacks on the property and places of worship of religious groups (Boyle \& Sheen, 1997). Buddhist temples were destroyed, and religions were persecuted outright. During this period, even the little freedom of writing about Buddhism vanished (Yang, 2004), and the government banned the people from having any religious beliefs (Stranger, 2006). The multiple regression analyses revealed that individualism/collectivism characteristics were most influential on negotiation styles. When negotiators understand this, they may accept and adopt the concept. Osman-Gani and Tan (2002) reported that people from individualistic cultures tend to be more concerned with their own rights, benefits, and outcomes; on the other hand, those from collectivist cultures tend to be more concerned with the overall group and social welfare. Drnevich (2003) indicated that people who are from cultures marked by a high level of power difference, uncertainty avoidance, masculinity, or individualism will have difficulty in achieving synergistic or integrative outcomes during negotiations.

The researcher suggests that the negotiators still need to be trained in body language, strategies, temper control, international manners, and customs. A better knowledge of negotiation should be helpful in understanding business and in realizing which negotiation styles are most appropriate for a particular country. The appropriate negotiation skills can bring more competitive advantages and benefits. Negotiators should create a database about negotiation knowledge that can be applied in different countries. The researcher also suggests that further training and drilling are required for negotiators, and that negotiators should focus on a culture's specific requirements rather than general principles. Although the strategies would be costly in the short-term, company owners who realize the benefits of negotiation stand to gain advantages that are more competitive in the long term. The participants were selected only from public companies, and were limited to CEOs and sales and purchase managers, and this study was constrained by person-power, financial resources, and time; therefore the study adopted only a quantitative research method. Future studies could compare the differences and similarities of negotiations in several countries, such as Asia's "four little dragons" or intra regions, such as Mainland China or Germany. 


\section{References}

Acuff, F. L. (1997). How to negotiate anything with anyone anywhere around the world. New York: AMACOM.

Barbash, I. \& Taylor, L. (1997). Cross-cultural filmmaking. Berkeley and Los Angeles, California: University of California Press.

Barry, S. (2001). Information sharing in global supply chain systems. Journal of Global Information Technology Management, 4(3), 27-50.

Bazerman, M. H., Curhan, J. R., Moore, D. A. \& Valley, K. L. (2000). Negotiation. Annual Review of Psychology, 51, 279-314.

Boyle, K. \& Sheen, J. (1997). Freedom of Religion and Belief: A World Report. London: Routledge.

Bray, M. \& Qin, G. (2001). Comparative education in greater China: contexts, characteristics, contrasts and contributions. Comparative Education, 37(4), 451-473.

Casse, P. \& Deol, S. (1985). Managing intercultural negotiations: Guidelines for trainers and negotiators. Washington, DC: International Society for Intercultural Educa.

Chua, P. \& Fujino, D. C. (1999). Negotiating new Asian-American masculinities: attitudes and gender expectations. Journal of Men's Studies, 7(3), 391.

D’Andrade, R. (1965). Cultural meaning system. Cambridge, UK: Cambridge University Press.

Demers, J. (2002). Negotiating skills can be learned: An increasing number of Canadian universities are offering courses on the art - and the science - of negotiations. CMA Management, 76(8), 33.

Drnevich, P. (2003). The role of cultural distance in international negotiations. Purdue University - Center for International Business Education and Research. Retrieved from http://www. mgmt. purdue. edu/centers/ciber/_publications/working papers. htm.

Fan, P. \& Zigang, Z. (2004). Cross-cultural challenges when doing business in China. Singapore Business Review, 26(1), 81-90.

Faure, G. O. \& Sjostedt, G. (1993). Culture and negotiation: An introduction. Newbury Park: Sage Publications.

Foroughi, A. (1998). Minimizing negotiation process losses with computerized negotiation support systems. Journal of Applied Business Research, 14(4), 15-27.

Fraser, C. \& Zarkada-Fraser, A. (2002). An exploratory investigation into cultural awareness and approach to negotiation of Greek, Russian and British managers. European Business Review, 14(2), 111-128.

Gannon, M. J. (2001). Understanding global cultures. Newbury Park: Sage Publications, Inc.

Gilsdorf, J. W. (1997). Metacommunication effects on international business negotiation in China. Business Communication Quarterly, 60(2), 20-38.

Goodwin, L. D. \& Goodwin, W. L. (1999). Measurement myths and misconceptions. School Psychology Quarterly, 14, 408-427.

Gu, E. X. (2001). Who was Mr. Democracy? The May Fourth Discourse of Populist Democracy and the Radicalization of Chinese Intellectuals (1915-1922). Modern Asian Studies, 35(3), 589-621.

Gulbro, R. D. \& Herbig, P. (1994). The effect of external influences in the cross-cultural negotiation process. Journal of strategic change, 3, 329-340.

Gulbro, R. D. \& Herbig, P. (1995). Cross-cultural negotiation behavioral differences: Domestic -focused versus worldwide-oriented firms. Cross cultural management, 2(3), 3-14.

Gulbro, R. D. \& Herbig, P. (1999). Cultural differences encountered by firms when negotiating internationally. Industrial Management + Data Systems, 99(2), 47-56.

Hayhoe, R. (1999). China's universities 1895-1995: a century of cultural conflict (Hong Kong, Comparative Education Research Centre, The University of Hong Kong).

Hofstede, G. (1980). Culture's consequences: international differences in work-related values. Beverly Hill, CA: - Sage Publications.

Hofstede, G. (1994). Cultures and organizations: Software of the mind: intercultural cooperation and its importance for survival. London: Harper Collins.

Hofstede, G. \& Bond, M. H. (1988). The Confucius connection: From cultural roots to economic growth. Organizational Dynamics, 16(4), 4-21.

Hung, C. L. (1998). Canadian business pursuits in the PRC, Hong Kong and Taiwan, and Chinese perception of Canadians as business partners. Multinational Business Review, 6(1), 73-83.

Janosik, R. J. (1987). Rethinking the culture-negotiation link. Negotiation Journal, 3, 385-395.

Korobkin, R. (2000). A positive theory of legal negotiation. George Law Journal, 88(6), 1789-1732.

Lee, D. Y. (2000). Retail bargaining behavior of American and Chinese customers. European Journal of 
Marketing, 34(1/2), 190.

Lin, R. (2006). Multivariate analysis: SPSS operation and application. Taipei: BestWise.

Manning, T. \& Robertson, B. (2003). Influencing and negotiating skills: Some research and reflections - Part I: Influencing strategies and styles. Industrial and Commercial Training, 35(1), 11-16.

Morris, D. J., Ettkin, L. P. \& Helms, M. M. (2001). China: The bitter roots of foreign business through the eyes of Asian culture. Competitiveness Review, 11(2), 25-39.

Neslin, S. \& Greenhalgh, L. (1983). Nash's theory of co-operative games as a predictor of the outcomes of buyer-seller negotiations: an experiment in media purchasing. Journal of Marketing Research, 20(4), 368-379.

Osman-Gani, A. M. \& Tan, J. S. (2002). Influence of culture on negotiation styles of Asian managers: An empirical study of major cultural/ethic group in Singapore. Thunderbird International Business Review, 44(6), 819-840.

Schein, E. H. (1997). Organizational culture \& leadership. CA: Jossey-Bass Inc.

Simintiras, A. C. \& Thomas, A. H. (1998). Cross-cultural sales negotiations: A literature review and research propositions. International Marketing Review, 15(1), 10-36.

Stranger, A. (2006). The Chicago connection. The American Scholar, 75(4), 5-10.

Volkema, R. J. \& Fleury, M. T. L. (2002). Alternative negotiating conditions and the choice of negotiation tactics: A cross-cultural comparison. Journal of Business Ethics, 36(4), 381-399.

Wallen, N. E. \& Fraenkel, J. R. (2001). Educational Research: A guide to the process (2nd ed.). Mahwah, NJ: Lawrence Erlbaum Associates, Inc.

Whitcomb, L. L., Erdener, C. B. \& Li, C. (1998). Business ethical values in China and the U.S. Journal of Business Ethics, 17(8), 839-853.

Woo, H. S. \& Prud'homme, C. (1999). Cultural characteristics prevalent in the Chinese negotiation process. European Business Review, 99(5), 313-315.

Yang, F. (2004). Between secularist ideology and desecularizing reality: the birth and growth of religious research in communist China. Sociology of Religion, 65(2), 101-120. 